\title{
1 Initial hydrogen isotopic composition of the solar system
}

4 J. Aléon ${ }^{1,}{ }^{*}$, D. Lévy ${ }^{1,2,3}$, A. Aléon-Toppani², H. Bureau ${ }^{1}$, H. Khodja ${ }^{4}$, F. Brisset ${ }^{5}$ 5

61 Institut de Minéralogie de Physique des Matériaux, de Minéralogie et de Cosmochimie,

7 Museum National d'Histoire, Naturelle, Sorbonne Université, UMR CNRS 7590, 61 rue

8 Buffon, 75005 Paris, France

92 Institut d'Astrophysique Spatiale, UMR 8617, CNRS, Univ. Paris-Saclay, Bât 120-121,

1091405 Orsay cedex, France

113 Laboratoire des Fluides Complexes et leurs Réservoirs (LFCR), E2S UPPA - Université

12 de Pau et des Pays de l'Adour, CNRS, Total, France

134 Université Paris-Saclay, CEA, CNRS, NIMBE, LEEL, 91191 Gif sur Yvette Cedex, France

145 Université Paris-Saclay, CNRS, Institut de Chimie Moléculaire et des Matériaux d'Orsay,

1591405 Orsay cedex, France

16

17 submitted to Nature Astronomy

18

19 *Corresponding author: jerome.aleon@mnhn.fr

20 ORCID: 0000-0001-5729-0166

21

22 
In spite of numerous studies, the initial isotopic composition of water in the solar system remains unknown. Here we use the isotopic composition of hydrogen in calcium, aluminum-rich inclusions (CAIs) from primitive meteorites, the oldest solar system rocks, to establish the hydrogen isotopic composition of water at the onset of solar system formation. We report the hydrogen isotopic composition of nominally anhydrous minerals from CAI fragments trapped in a once-melted host CAI. Primary minerals have extremely low $\mathrm{D} / \mathrm{H}$ ratios, with $\delta \mathrm{D}$ values down to $850 \%$, recording the trapping of nebular hydrogen. FeO-rich minerals formed before capture of the fragments record the existence of a nebular gas reservoir with an oxygen fugacity significantly above solar and a D/H ratio within $20 \%$ of that of the Earth oceans. $H$ isotopes further correlate with oxygen and nitrogen isotopes indicating that planetary reservoirs of volatile elements formed within the first $2 \times 10^{5}$ years of the solar system, during the main CAI formation epoch. We propose that the isotopic composition of inner solar system water was established during collapse of the protosolar cloud core owing to a massive admixture of interstellar water.

As water is a major ingredient in the recipe of planet formation and origin of life, its origin and chemistry and notably its $\mathrm{H}$ and $\mathrm{O}$ isotopic compositions have extensively been studied and modeled in solar system objects ${ }^{1-5}$. H isotopes indicate injection of Drich molecules from the cold interstellar medium / outer protoplanetary disk into the inner regions where terrestrial planets formed and have widely been used as a tracer of water origin. However, the initial isotopic composition of water in the protoplanetary disk has always been lacking so that models often rely on astronomical observation of remote forming stellar systems. In addition, most models consider static T-Tauri disks ${ }^{2-4}$ and neglect the fact that the $\mathrm{D} / \mathrm{H}$ ratio of water probably evolved during the diskbuilding phase. However, a few models have shown the influence of this early phase, not only on the distribution of $\mathrm{D} / \mathrm{H}$ ratios $^{5}$, but also on other isotopic and chemical properties of early planetary materials ${ }^{6}$. A correct understanding of D/H systematics in the solar system and origin of water in planetary bodies thus require to know the isotopic composition of $\mathrm{H}$ as recorded in the most ancient solar system materials formed 
CAIs are the oldest solar system rocks ${ }^{7}$ and their mineralogy, chemistry and isotopic composition are commonly used as benchmarks to establish the physico-chemical conditions at the onset of planetary formation. They formed primarily by condensation at high temperature of refractory solids from a gas of solar composition in the innermost solar system, grew by coagulation and subsequently experienced various degrees of reheating up to the point of partial melting and eventually late modifications on their asteroidal parent-bodies ${ }^{8}$. Measuring the hydrogen isotopic composition of nominally anhydrous minerals formed below $100 \mathrm{~Pa}$ and at $1200-1500^{\circ} \mathrm{C}$ is challenging, especially given that most meteorites experienced fluid circulations after accretion, which could have masked a primary composition inherited from the protoplanetary disk. Compound CAIs (i.e. composed of several lithological units that were once individual CAIs) from the least altered and least metamorphosed chondrites are choice targets to identify preserved pre-accretionary nebular isotopic signatures. Efremovka 101.1 (E101.1, Fig. 1 ) is a compound CAI from the reduced CV3 chondrite Efremovka, a petrologic type 3.13.4 chondrite $^{9}$, i.e. having suffered only modest amounts of metamorphic modifications and little fluid circulations. It contains fragments of a first CAI rich in Al-diopside trapped in a once-melted melilite-rich host CAI that underwent only little alteration ${ }^{10,11 .}$ $\mathrm{O}, \mathrm{Mg}$ and $\mathrm{Si}$ isotopes demonstrate that the Al-diopside-rich fragments (hereafter xenoliths) were initially foreign to the host CAI and were captured while the host was still partially molten ${ }^{11}$. The xenoliths contain an unusual assemblage of secondary minerals replacing primary minerals and having formed in oxidizing conditions before capture of the xenolith by the host (ref 12 and supplementary material). Using NanoSIMS imaging ${ }^{13}$, we estimated the $\mathrm{H}$ content and measured the H isotopic composition of individual $\mu \mathrm{m}$-sized minerals from E101.1 xenoliths, with the aim to identify pristine nebular $\mathrm{H}$ components predating the capture of the xenoliths by the host. Targeted minerals include (i) primary Al-diopside, (ii) anorthite whose primary or secondary nature is often debated in CAIs, (iii) secondary kirschsteinite occurring both as coarse $\mu \mathrm{m}$-sized Fe-rich crystals and as fine-grained aggregates of $100 \mathrm{~nm}$-sized Mgenriched crystals sometimes associated with nanoscale diopside and minute Fe metal, (iv) Fe-rich åkermanite, a type of secondary melilite unusual in CAIs and (v) secondary wollastonite. For comparison, we measured the glass in melt pockets resulting from impact melting of the host-xenoliths interface, as well as melilite and secondary phases from the host CAI (a Na-rich phase and alteration in a fracture). 
90 The distribution of $\mathrm{D} / \mathrm{H}$ as a function of $\mathrm{H}^{-}$secondary ion intensity, a proxy for the $\mathrm{H}$ content (methods), which can be expressed as equivalent water content, shows a trimodal distribution in E101.1 with two hydrogen poor-components having large Dexcesses with $\delta \mathrm{D}$ values up to $+1000 \%$ and deficits down to $\delta \mathrm{D}$ values of $-850 \%$ (Fig. 2), with $\delta \mathrm{D}$ being the deviation relative to the Earth oceans given in \%o. The third component is a hydrogen-rich component $\left(\mathrm{H}_{2} \mathrm{O} \geq \sim 3.5 \mathrm{wt} \%\right)$ with a $\delta \mathrm{D}$ value of $\sim 0 \%$, restricted to secondary minerals outside the xenoliths. When only xenoliths analyses are considered, the range of $\mathrm{H}$ content and $\mathrm{D} / \mathrm{H}$ composition is well accounted for by a three-component mixing between the D-rich, D-poor components and a component with intermediate $\mathrm{H}$ content $\left(\sim 0.5 \mathrm{wt} \% \mathrm{H}_{2} \mathrm{O}\right)$ and a $\delta \mathrm{D}$ value of $\sim 0 \%$ o (Fig. $2 \mathrm{~b}$ and

100 Supplementary Fig.1). This mixing is partially of analytical origin due to the relatively large size of the ion beam used for the analyses $(\sim 1.5 \mu \mathrm{m})$ relative to the mineral grain size (100 $\mathrm{nm}$ to a few $\mu \mathrm{m})$ but reflects also the intermediate composition of homogeneous phases, such as that of the impact glass. None of these components can be ascribed to analytical contamination (methods). Furthermore, residual contamination would only contribute to a decrease of the most extreme values, which must be considered as indicating minimal D-depletion and D-enrichment, respectively. We therefore consider the measured values as conservative estimates. Textures and mineralogy further rule out the contribution of terrestrial weathering before collection of the Efremovka meteorite (supplementary material).

111 The $\delta \mathrm{D}$ value of the first xenolith component observed in anorthite and diopside at $112850 \%$ is equal to that of nebular $\mathrm{H}_{2}$. Within error, it cannot be distinguished from pure 113 solar protons $(\delta \mathrm{D}=-1000 \%$ ). Negatively fractionated $\mathrm{Mg}$, Si isotopes and near solar $\mathrm{O}$ 114 isotopes in diopside ${ }^{11}$ with $\Delta^{17} \mathrm{O}=-20 \%$ and petrological context (ref 12 and 115 supplementary material) support formation of diopside by condensation from a solar 116 gas. Hence, this isotopic composition can be ascribed to trapping of solar $\mathrm{H}_{\text {or }} \mathrm{H}_{2}$ in the 117 crystal structure during condensation. Most likely, $\mathrm{H}$ is present in diopside and anorthite 118 as protonated point defects or molecular $\mathrm{H}_{2}$ dissolved in the crystal lattice. The 119 measured $\mathrm{H}$ signal is consistent with $\sim 500 \mathrm{ppm}$ equivalent water $\left(\sim 55 \mathrm{ppm} \mathrm{H}_{2}\right)$, which 120 is surprisingly high, a common observation in meteoritic NAMs ${ }^{14,15}$. Whereas low 121 pressures in the nebula are not in favor of storage of a significant amount of $\mathrm{H}$ in the 
structure of NAMs, the solubility of $\mathrm{H}_{2}$ increases with $\mathrm{fH}_{2}$ (ref 16), which may favor the solubilization of $\mathrm{H}_{2}$ in clinopyroxene (diopside) and anorthite, as $\mathrm{H}_{2}$ is by far the dominant gas species. Alternatively, significant $\mathrm{H}$ abundance may result from the trapping of protons in a solar plasma. Note that anorthite has the lowest $\delta \mathrm{D}$ value found in meteorites, which rules out a secondary and a parent-body origin of anorthite.

\section{$\mathrm{Ca}, \mathrm{O}, \mathrm{Si}$ and Fe are the main targets for the production of $\mathrm{D}$ by spallation. As they are} major elements in all xenolith minerals, whereas the D-excesses are restricted to finegrained kirschsteinite aggregates, the latter cannot be ascribed to spallation. The association of D-excesses with low $\mathrm{H}$ contents also rules out alteration in a D-rich fluid, which would result in high $\mathrm{D} / \mathrm{H}$ ratios associated with high $\mathrm{H}$ content. By contrast, the Dexcesses are well accounted for by kinetic fractionation during intra-crystalline diffusion of $\mathrm{H}$ atoms (Fig. 2b) driven by $\mathrm{H}$ loss, independently of the speciation of the lost molecule. Such a kinetic fractionation has been demonstrated in grossular ${ }^{17}$, another Carich nesosilicate, where fractionation was attributed to the migration of protonated point defects driven by water loss. Mineralogy shows that fine-grained kirschsteinite formed during capture of the xenoliths by reduction of coarse-grained kirschsteinite (ref 12 and supplementary material). The latter has a large range of $\mathrm{H}$ content and its highest H content ( $~ 5000$ ppm) and Earth-like isotopic composition (within 20\%) are consistent with those of the precursor expected from the diffusive loss calculations (Fig. 2b). Therefore deuteration occurred during reduction of coarse-grained kirschsteinite, and capture of the xenoliths by the partially molten host. This implies that coarsegrained kirschsteinite formed before accretion of the CV chondrite parent-body in an oxidizing nebular gas reservoir having an Earth-like D/H ratio within 20\%. All minerals from the host CAI also have Earth-like isotopic composition, including Na-rich minerals with $\mathrm{H}_{2} \mathrm{O}$ content up to $\sim 3.5$ wt $\%$ and igneous melilite with $\mathrm{H}_{2} \mathrm{O}$ content $\leq 5000$ ppm.

The H isotope systematics of E101.1 thus points toward the co-existence of two gaseous reservoirs during the earliest phase of solar system formation. Although the speciation of $\mathrm{H}$ in minerals, notably in NAMs, is different from that in the gas, the relationship between $\mathrm{H}$ isotopes and redox state indicates that condensate diopside and anorthite recorded the composition of the solar nebular hydrogen gas, while FeO-rich secondary minerals and possibly igneous melilite recorded the composition of a water-enriched 
nebular gas with Earth-like $\mathrm{H}$ isotopic composition. Given that a warm environment is required for kirschsteinite formation, water and hydrogen were most likely in isotopic equilibrium. The 0 isotopes we measured previously in E101.1 (ref. 11) show a similar systematics with condensate diopside having a typical near solar ${ }^{16} 0$-rich composition, whereas $\mathrm{FeO}$-rich minerals and igneous melilite have a planetary-like ${ }^{16} \mathrm{O}$-poor isotopic composition. This $\mathrm{O}$ isotope systematics is common in igneous CAIs and attributed to interactions between a precursor of solar composition with a nebular gas reservoir of planetary composition ${ }^{18,19}$. Hence $\mathrm{H}$ and $\mathrm{O}$ isotopes in CAIs show a co-existence of $\mathrm{H}$ and 0 isotopes with light near-solar composition $\left(\delta \mathrm{D} \sim-850 \%\right.$ and $\Delta^{17} \mathrm{-} \sim-25 \% 0$ ) in condensate minerals and planetary isotopic composition $\left(\delta \mathrm{D} \sim \Delta^{17} \mathrm{O} \sim 0 \% \mathrm{0}\right)$ in minerals processed in the solar nebula. This relationship suggests that the planetary composition is carried by water vapor. $\mathrm{N}$ isotopes show a similar systematics, with TiN in a condensate CAI having a near solar $\delta^{15} \mathrm{~N}$ value at $-364 \% 0^{20}$, while an igneous CAI has a planetary-like composition at $\delta^{15} \mathrm{~N} \sim 0 \%{ }^{21}$. This indicates that $\mathrm{H}, \mathrm{O}$ and $\mathrm{N}$ isotopes coevolved from a near solar composition to a planetary composition (Fig. 3) during the formation of igneous CAIs, in the first 200,000 years of the solar system, while the presolar cloud envelope was still collapsing 22 . The relationship between $\mathrm{N}$ isotopes and heavy metal nucleosynthetic anomalies in iron meteorites ${ }^{23}$ further testifies that the planetary $\mathrm{N}$ reservoir built up during early infall of interstellar material.

Hence, the ubiquitous $\mathrm{H}$ isotopic composition (D/H $\sim 1-2 \times 10^{-4}$ ) observed in large earlyformed telluric planetesimals such as the howardites-eucrites-diogenites (HED) parentbody (Vesta) or the angrite parent-body and in the mantle of the Earth and Mars was reached in the first few $10^{5}$ years of the solar system owing to a massive influx of interstellar matter infalling directly in the inner solar system ${ }^{24}$, rather than being produced in a more evolved protoplanetary $\operatorname{disk}^{2,3}$. Accretion of primitive materials at different stages of infall allows for some isotopic heterogeneity between planetesimals (supplementary discussion). The relationship observed for $\mathrm{H}, \mathrm{O}, \mathrm{N}$ isotopes between the Sun, condensate CAIs and planetary gas (Fig. 3) suggests that igneous CAIs formed from solar matter at the inner edge of the protoplanetary disk, and were processed to some extent in the planetary gas. Raising the bulk $\mathrm{D} / \mathrm{H}$ ratio of the disk to the planetary value by addition of interstellar water having a typical $\mathrm{D} / \mathrm{H}$ ratio between $10^{-3}$ and $10^{-2}$ would require an enhancement of the ice/gas ratio of a factor 10 to 100, which in turn would 
188

189

190

191

192

193

194

195

196

197

198

199

200

201

202

203

204

205

206

207

208

209

210

211

212

213

214

215

216

217

218

increase the $\mathrm{fO}_{2}$ of the gas by 2 to 4 orders of magnitude. In-situ production of Dexcesses by chemical reactions in a plasma ${ }^{25}$ could be an alternative hypothesis (supplementary discussion) provided it is associated with mass independent fractionation of oxygen ${ }^{26}$ and a change in redox conditions.

\section{Methods}

Sample description. Efremovka 101.1 is a complex compound CAI consisting of multiple lithological units, all characterized by ultra-refractory Rare Earth Elements (REE) patterns ${ }^{10}$. $0, \mathrm{Mg}$ and $\mathrm{Si}$ isotopes have demonstrated that sinuous fragments dominated by Al-diopside have an extraneous origin and were captured by the host inclusion in a partially molten state ${ }^{11}$. An unusual FeO-rich mineral assemblage is associated with and restricted to these xenoliths. The detailed mineralogical study of the xenolith and their mineral assemblage is beyond the scope of the present study, but major observations obtained by scanning electron microscopy, electron probe microanalysis and transmission electron microscopy from a preliminary report ${ }^{12}$ are recalled here and as supplementary materials to support the H isotope study.

The host E101.1 CAI is a compact type A CAI consisting mainly of Al-rich melilite (Åk2030, refs 10-11), which contains Al-Mg spinel aggregates and metal grains associated with perovksite and Sc-Zr-rich clinopyroxene and locally with anorthite intergrown with a Na-rich mineral postulated to be nepheline ${ }^{11}$. By contrast, E101.1 xenoliths consist predominantly of Al-bearing diopside, associated with anorthite and containing pockets of FeO-rich minerals characterized as (1) a $\mu$ m-sized Ca-Fe-rich olivine (hereafter coarse-grained (CG) kirschsteinite, kir), (2) a fine-grained (FG) aggregate of $100 \mathrm{~nm}$ crystals of kirschsteinite enriched in Mg relative to CG-kir plus minute Fe metal grains and in some cases fine-grained Fe-rich diopside (Supplementary Fig.2), (3) an unusual Mg-Fe-rich melilite (hereafter Fe-åkermanite) (Supplementary Fig.3). CG-kir has a composition on the join kirschteinite-monticellite with $61-79$ mol\% kir, while kir in the FG-assemblage is enriched in Mg with a wide range of composition ranging from 68 mol\% kir to 17 mol\% kir. These FeO-rich minerals are associated with wollastonite ${ }^{12}$. Veins filled with a Ca-poor amorphous phase crosscut all mineral assemblages from the xenoliths and extend into the host ${ }^{12}$ (Supplementary Fig.2). Finally melt pockets up to $100 \mu \mathrm{m}$ in size and containing melilite dendrites and fractured Al-diopside crystals are 
221 observed at the xenolith-host interface (Supplementary Fig 4). The distribution of Fe, $\mathrm{Na}$ 222 and Ni throughout the compound CAI (Supplementary Fig.5) shows (i) high abundance

223 of $\mathrm{Na}$ and $\mathrm{Fe}$ associated with the xenoliths and with metal-anorthite-nepheline

224 inclusions, (ii) Fe enrichment in spinel limited to the outermost $30 \mu \mathrm{m}$ of the CAI

225 periphery and (iii) Fe and Na associated with sub-parallel impact induced compaction

226 fractures either connected to the outer rim or to FeNi metal beads.

NanoSIMS imaging of FIB sections. D/H ratios were measured by NanoSIMS at Institut de Minéralogie de Physique des Matériaux et de Cosmochimie, Paris, France, using optimal analytical conditions determined in ref 13. 5 Focused Ion Beam (FIB) sections $(\sim 10 \times 5$ $\mu \mathrm{m}$ ) of $2 \mu \mathrm{m}$ thickness prepared at Institut d'Electronique, Microélectronique et Nanotechnologie, Lille, France, were extracted from the E101.1 CAI with the aim to sample all minerals and mineral associations encountered in the xenoliths and were deposited on a polished $\mathrm{Al}$ disk and coated with $\mathrm{Au}$. All reference minerals including standard amphiboles and terrestrial NAMs were prepared similarly. Each analysis consisted of an $8 \mu \mathrm{m} \times 8 \mu \mathrm{m}$ image acquired using a $\sim 1.5 \mu \mathrm{m}$ Cs + beam of $100 \mathrm{pA}$ and 8 $\mathrm{kV}$. A 250 pA Cs ${ }^{+}$beam was rastered over $20 \times 20 \mu \mathrm{m}$ during $8 \mathrm{~min}$ before analysis to remove $\mathrm{Au}$, sputter clean the sample and achieve sputtering equilibrium. Electron flooding was used for charge compensation. $\mathrm{H}$ and $\mathrm{D}$ were collected simultaneously on two electron multipliers using a $1000 \mu \mathrm{s} /$ pixel dwell time. 256 x 256 pixels images consist of 20 planes acquired sequentially during 20 minutes. Secondary and backscattered electron images of the sections were acquired by Field Emission GunScanning Electron Microscopy (FEG-SEM) at Institut de Chimie Moléculaire et des Matériaux d'Orsay, Orsay, France, after NanoSIMS analysis to identify minerals remaining in the sections at the end of the analyses.

Image processing. For all FIB sections, two different types of image processing were applied (Supplementary Fig.6). (1) All images were subdivided in squares having the size of the primary beam, i.e. the lateral resolution of the analyses. These squares are referred to as xenolith ROIs and host ROIs depending on the FIB section. ROIs along the edges of the images were eliminated. For each ROI the D/H ratio was determined from the $\mathrm{H}$ and $\mathrm{D}$ ion counts extracted in the image using the LIMAGE software ((c) Larry Nittler, 1997), and uncertainties were determined using counting statistics following a 
254 Poisson law. (2) Subsequently, additional ROIs corresponding to minerals identified 255 with FEG-SEM images of the sections acquired after analysis were hand-drawn, taking 256 care to define ROIs at least equal to the primary beam size in order to avoid under257 sampling and statistical error. These are referred to as Mineral ROIs. D/H ratios were 258 determined similarly. Counting statistics, reproducibility between acquisition cycles, 259 reproducibility on the standards and uncertainty due to FIB section heterogeneities on 260 standards ${ }^{13}$ (all standard errors of the mean) were quadratically taken into account to 261 determine the analytical errors. For both image processing, D/H ratios were determined 262 using total ions counts over the course of an image acquisition rather than using the 263 average of individual image planes, some of which may have $0 \mathrm{D}$ counts, to avoid biases 264 in the $\mathrm{D} / \mathrm{H}$ ratios due to improper correction ${ }^{27}$.

Correction of instrumental mass fractionation (IMF). To correct for instrumental bias

267 (referred to as IMF and denoted alpha), we used the Fe-rich arfvedsonite Illimaussaq 268 and Mg-rich hastingsite Bamble amphiboles to encompass a large range of possible mass 269 fractionation for $\mathrm{H}$ isotopes in minerals ${ }^{28}$. A basaltic glass with intermediate water 270 content (SW-DR32-1-1) yielded a similar mass fractionation as Bamble (Supplementary 271 Table 1).

272 We used Bamble to correct IMF for Fe-poor minerals and areas on FIB sections and SW273 DR32-1-1 to correct IMF for glass in E101.1 CAI (of close to basaltic composition). For 274 the Fe-rich minerals and Fe-rich areas we applied two corrections using either Bamble 275 or Ilimaussaq and compared the effects of the corrections. This is illustrated in Fig. S1 276 where the most hydrogen-rich Fe-rich minerals and Fe-rich areas have similar 277 composition to the water-rich Fe-poor samples if corrected similarly with Bamble. By 278 contrast, correction with Illimaussaq yield a systematic offset equal in amplitude to the 279 Bamble-Illimaussaq difference in alpha in these minerals suggesting that Fe-rich NAMs 280 behave similarly to Fe-poor samples rather than to Fe-rich hydroxylated silicates. 281 Additionally, terrestrial NAMs yield uncorrected values comparable to Bamble/SW282 DR32-1-1 within error, including the Fe-rich andradite, in line with this observation.

283 A possible explanation would be a different crystallographic control on the mass 284 fractionation. Indeed the IMF in hydroxylated minerals is controlled by total electronegativity in the $\mathrm{OH}$ octahedral site, which can be approximated by the $\mathrm{Fe} / \mathrm{Fe}+\mathrm{Mg}$ 286 ratio ${ }^{29}$. But in NAMs such as kirschsteinite, there is no such octahedral site, as $\mathrm{H}$ is 
included mostly as point defects in the crystalline network ${ }^{17}$. We thus suspect that Ferich NAMs such as kirschsteinite are associated with a mass fractionation comparable to that of Fe-poor minerals. In the absence of a Fe-rich NAM sample with well-documented $\mathrm{D} / \mathrm{H}$ ratios, it is not possible to conclude what would be the best correction to apply for the instrumental mass fractionation. However, either correction does not change our conclusions, so we use Bamble correction for the main text, as it is the most conservative in terms of $\mathrm{D} / \mathrm{H}$ ratio amplitude, and provide results with the alternative correction in supplementary information (Supplementary Tables 2,3, Supplementary Fig.1).

Water content. To measure water content we used 8 reference minerals with a large range of water content: Illimaussaq and Bamble amphiboles (1.6 and $2.0 \mathrm{wt} \% \mathrm{H}_{2} \mathrm{O}$, respectively), SW-DR32-1-1 glass and NAMs, whose $\mathrm{H}$ content was determined using ERDA at the nuclear microprobe at the Laboratoire d'Etude des Elements Légers, CEA, Saclay, France following analytical procedures described in ref 29. Those include andradite, grossular and nepheline, which are common CAI alteration minerals. Residual surface contamination in NanoSIMS was estimated using a San Carlos olivine, which H content is lower than 30 ppm equivalent $\mathrm{H}_{2} \mathrm{O}$ by weight. To obtain precise $\mathrm{H}$ or water content, the $\mathrm{H}^{-} / \mathrm{O}^{-}$or $\mathrm{H}^{-} / \mathrm{Si}^{-}$ratios are usually measured in SIMS in given minerals to overcome analytical effects known as matrix effects. Here, given the complexity of the mineral assemblages in E101.1 xenoliths, their ultra-fine grained and unusual nature, it has not been possible to overcome these matrix effects. Rather, we established that over a very large range of content and for silicate matrices reasonably close to those in E101.1, the $\mathrm{H}^{-}$secondary ion signal is proportional to the $\mathrm{H}$ content to a first approximation (Supplementary Fig.7). Assuming a typical background contamination of about 200 ppm equivalent $\mathrm{H}_{2} \mathrm{O}$ as established previously ${ }^{13}$, the average deviation of the standards data from the linear regression is $\sim 21 \%$, which indicates that well-known matrix effects can be ignored provided that the hydrogen content is approximated

314 within $20 \%$ as equivalent water content by weight (Supplementary Fig.7). Note that the 315 NSH9 pyroxene, which is the only NAM not measured by ERDA and for which we used a 316 literature value ${ }^{30}$, plots outside the $\mathrm{H}$ signal vs $\mathrm{H}_{2} \mathrm{O}$ concentration correlation and was thus not included in the regression. 
Validity of the measured D/H ratios. Given the low D signal of many ROIs, we ensured the validity of the determined $\mathrm{D} / \mathrm{H}$ ratios first by comparing the measured $\mathrm{D} / \mathrm{H}$ ratios with

321 those of terrestrial reference materials measured in the same session with the same analytical conditions, including the standard amphiboles and basaltic glass but NAMs of unknown true D/H ratios as well. Supplementary Fig.8 shows that even at very low count rates terrestrial references exhibit $\mathrm{D} / \mathrm{H}$ ratios within the terrestrial range, whereas the extreme values measured in the E101.1 xenoliths are well outside this range by several hundreds of per mil and more than $3 \sigma$ uncertainties, indicating with more than $99.7 \%$ confidence that the observed range cannot be an artifact of analytical origin.

329 Then, we calculated the theoretical uncertainty on a sample having a D/H ratio of. $1.55 \times$ $10^{-4}$ equal to that of the Standard Mean Ocean Water as a function of $\mathrm{H}$ intensity. We included the Poisson counting statistics, the reproducibility on standards and the reproducibility within a FIB section in the calculation. As visible on Supplementary Fig.9, the extreme values measured in the E101.1 xenoliths plot well outside the $3 \sigma$ error envelope indicating again with more than $99.7 \%$ confidence that the measured range of $\mathrm{D} / \mathrm{H}$ ratios range is not of statistical origin. As a result, we are confident that the observed variations are indeed indigenous to the samples and cannot be artifacts, in spite of large uncertainties due to the low D counting rates.

338 Finally, a common issue in the analysis of $\mathrm{D} / \mathrm{H}$ ratio in meteorites, including by SIMS, is 339 the contribution of $\mathrm{H}$ from organic matter associated with hydrated minerals. This is usually overcome by measuring simultaneously the $\mathrm{D} / \mathrm{H}$ and $\mathrm{C} / \mathrm{H}$ ratios and extrapolating $\mathrm{D} / \mathrm{H}$ ratios to $\mathrm{C} / \mathrm{H}=0$ (e.g. ref 31 ). This approach is useful for fine-grained materials composed of mixtures of phyllosilicates and organics analyzed in bulk (or at

343 the scale of SIMS analysis). By contrast, here we performed highly localized analysis of 344 anhydrous minerals in regions devoid of matrix materials and organics, thus ensuring that the measured $\mathrm{D} / \mathrm{H}$ ratios are free of organic contributions.

Calculations of Rayleigh fractionation. We compared the amplitude of D-excesses in the

348 FG-kirschsteinite assemblage with the D-enrichments that could be achieved upon kinetic fractionation and Rayleigh distillation during $\mathrm{H}$ loss. The calculations were performed for three cases: using the kinetic fractionation factor for $\mathrm{H}$ mobility (case of intra-crystalline $\mathrm{H}$ diffusion), for $\mathrm{H}_{2}$ mobility (evaporation of $\mathrm{H}_{\text {as }} \mathrm{H}_{2}$ ) and $\mathrm{OH}$ mobility 
(evaporation of $\mathrm{H}$ as $\mathrm{OH}$ ), where the kinetic fractionation factors are $\alpha=\sqrt{ }$

353 (MDspecies/MHspecies), with M being the molecular mass, i.e. $\alpha=\sqrt{2}, \alpha=\sqrt{ }(3 / 2)$ and $\alpha=\sqrt{ }$

354 (18/17), respectively. The $\mathrm{H}_{2} \mathrm{O}$ case was not evaluated as it is close to the $\mathrm{OH}$ case but of 355 even lower amplitude. Different situations were investigated for each case: (1) differing

356 initial water content, (2) differing initial D/H ratios and (3) data for Fe-rich

357 minerals/areas corrected with either Illimaussaq or Bamble amphibole. Apart one

358 simulation of $\mathrm{H}_{2}$ loss with unrealistically high initial water content of at least $2.5 \mathrm{wt} \%$,

359 we found that only $\mathrm{H}$ mobility provides a good fit to the data, whereas $\mathrm{H}_{2}$ loss falls short

360 to produce the observed D-excesses (Supplementary Fig.10). Therefore the D-excesses

361 observed in FG-kirschsteinite can be attributed to $\mathrm{H}$ mobility upon intra-crystalline

362 diffusion driven by $\mathrm{H}$ loss, independently of the speciation of $\mathrm{H}$ in the lost molecule.

\section{Data availability statement}

365 All the data used in the manuscript are presented in the supplementary tables and any

366 other request or correspondence should be addressed to Jérôme Aléon.

\section{Acknowledgements}

369 Discussions with Laurent Remusat and François Robert and help from the NanoSIMS staff Rémi Duhamel and Adriana Gonzalez-Cano were appreciated. The FIB section preparation was partly supported by the French Renatech network. David Troadec is warmly thanked. This work was supported by ATM grants from the Museum National d'Histoire Naturelle and by the French National Program of Planetology PNP INSU/CNRS.

\section{Authors contribution}

JA and AAT designed and supervised the study. DL characterized the sample, performed the NanoSIMS analyses and reduced the data. HB and HK characterized the standards by ERDA. FB performed SEM imaging of the FIB sections. JA, AAT and DL interpreted the data. JA and AAT wrote the manuscript with input from all others co-authors. 
Supplementary information is available for this paper.

\section{Figure Legends}

387 Figure 1. Petrographic description of CAI Efremovka 101.1. a. Backscattered electron 388 image of the whole CAI. Arrows show the sinuous xenolithic fragments. Dashed box :

389 contour of image in b. b. Detail of a xenolith, backscattered electron image, dashed box : contour of image in c. c. False color multi-element combined X-ray map showing the mineralogy of the xenolith. CG kir = coarse-grained kirschsteinite; FG = fine-grained assemblage; $\mathrm{di}=\mathrm{Al}$-diopside; an = anorthite; Fe-åk = Fe-rich åkermanite; wo =

393 wollastonite; $\mathrm{gl}=$ glass.

395 Figure 2. Distribution of hydrogen isotopic composition shown as $\delta \mathrm{D}$ values as a 396 function of $\mathrm{H}^{-}$secondary ion intensity and equivalent $\mathrm{H}_{2} \mathrm{O}$ content. a. All data. b. data 397 from the xenoliths only and predictions of D enrichments upon $\mathrm{H}$ loss for several 398 mechanisms. The maximal D-excesses are only matched by intra-crystalline diffusion of $\mathrm{H}$ atoms. Errors are 2 standard errors of the mean. Al, Ti cpx : Al,Ti-rich clinopyroxene.

Figure 3. Comparison between $\mathrm{H}$ isotopes and isotopes of other volatile elements in 402 CAIs and planetary components. a. Comparison between $\mathrm{H}$ and $\mathrm{O}$ isotopes. $\mathrm{b}$.

403 Comparison between $\mathrm{H}$ and $\mathrm{N}$ isotopes. Error bars: 2 standard error of the mean on $\mathrm{H}$ 404 isotopes (this work) and 0 isotopes ${ }^{11}$. hib/gros CAIs = hibonite-rich and/or grossite-rich 405 CAIs.

406

407

\section{References}

408 1. Robert, F. The origin of water on Earth. Science 293, 1056-1058 (2001).

409

2. Drouart, A., Dubrulle, B., Gautier, D. \& Robert F. Structure and transport in the solar nebula from constraints on deuterium enrichment and giant planets formation. Icarus 140, 129-155 (1999). isotopic composition of chondrites. Icarus 223, 722-732 (2013). 
4. Cleeves, L. I., et al. The ancient heritage of water ice in the solar system. Science 345,

418 1590-1593 (2014).

419

420

5. Yang, L., Ciesla, F. J. \& Alexander, C.M.O'D. The D/H ratio of water in the solar nebula during its formation and evolution. Icarus 226, 256-267 (2013).

422

423

6. Pignatale, F. C., Charnoz, S., Chaussidon, M. \& Jacquet, E. Making the planetary material 424 diversity during the early assembling of the solar system. Astrophys. J. Lett 867, L23, 7pp 425 (2018).

426

427

7. Connelly, J. N., et al. The absolute chronology and thermal processing of solids in the 428 solar protoplanetary disk. Science 338, 651-655 (2012).

429

430

8. MacPherson, G. J. Calcium-aluminum-rich inclusions in chondritic meteorites. in

431 Meteorites and Cosmochemical Processes (ed. Davis, A. M.), 139-179 (Treatise on

432 Geochemistry vol 1, 2nd edition, Elsevier, 2014).

433

9. Bonal, L., Quirico, E., Bourot-Denise, M. \& Montagnac, G. Determination of the

435 petrologic type of CV3 chondrites by Raman spectroscopy of included organic matter. Geochim. Cosmochim. Acta 70, 1849-1863 (2006).

437

438

10. El Goresy, A., et al. Efremovka 101.1: A CAI with ultrarefractory REE patterns and 439 enormous enrichments of Sc, Zr and Y in fassaite and perovskite. Geochim. Cosmochim. Acta 66, 1459-1491 (2002). distributions in the complex ultra-refractory CAI Efremovka 101.1: Assimilation of ultrarefractory, FUN, and regular CAI precursors. Geochim. Cosmochim. Acta 232, 48-81 445 (2018). (2019). 
13. Lévy, D., et al. NanoSIMS imaging of D/H ratios on FIB sections. Anal. Chem. 91, 13763-13771 (2019).

453

14. Stephant, A., Remusat, L. \& Robert, F. Water in type I chondrules of Paris CM

455 chondrite. Geochim. Cosmochim. Acta 199, 75-90 (2017).

456

15. Piani, L., et al. Earth's water may have been inherited from material similar to enstatite chondrite meteorites. Science 369, 1110-1113 (2020).

459

460

16. Yang, X., Keppler, H. \& Li, Y. Molecular hydrogen in mantle minerals. Geochem. Persp.

461 Lett. 2, 160-168 (2016).

462

463

17. Roskosz, M., et al. Kinetic D/H fractionation during hydration and dehydration of silicate glasses, melts and nominally anhydrous minerals. Geochim. Cosmochim. Acta

465

466

467

468

469

470

471

472

473

474

475

476

477

478

479

480

481

22. Brennecka, G. A., et al. Astronomical context of Solar System formation from molybdenum isotopes in meteorite inclusions. Science 370, 837-840 (2020).

18. Yurimoto, H., Ito, M. \& Nagasawa, H. Oxygen isotope exchange between refractory inclusion in Allende and solar nebula gas. Science 282, 1874-1877 (1998).

19. Aléon, J. Oxygen isotopes in the early protoplanetary disk inferred from pyroxene in a classical type B CAI. Earth Planet. Sci. Lett. 440, 62-70 (2016).

20. Meibom, A., et al. Nitrogen and carbon isotopic composition of the Sun inferred from a high-temperature solar nebula condensate. Astrophys. J. 656, L33-L36 (2007).

21 Füri, E., Chaussidon, M. \& Marty, B. Evidence for an early nitrogen isotopic evolution in the solar nebula from volatile analyses of a CAI from the CV3 chondrite NWA 8616. Geochim. Cosmochim. Acta 153, 183-201 (2015).

\section{9}


483

484

485

486

487

488

489

490

491

492

493

494

495

496

497

498

499

500

501

502

503

504

505

506

507

508

509

510

511

512

513

23. Grewal, D. S., Dasgupta, R. \& Marty, B. A very early origin of isotopically distinct nitrogen in inner Solar System protoplanets. Nature Astron., doi.org/10.1038/s41550020-01283-y (2021).

24. Lee, Y.-N., Charnoz, S. \& Hennebelle, P. Protoplanetary disk formation from the collapse of a prestellar core. Astron. Astrophys. 648, A101, DOI: 10.1051/0004$6361 / 202038105$ (2021).

25. Robert, F., Derenne, S., Lombardi, G., Hassouni, K., Michau, A., Reinhardt, P., Duhamel, R., Gonzalez, A., Biron, K. Hydrogen isotope fractionation in methane plasma. Proc. Nat. Acad. Sci. 114, 870-874 (2017).

26. Thiemens, M. H. History and Applications of Mass-Independent Isotope Effects. Annu. Rev. Earth Planet. Sci. 34, 217-262 (2006).

27. Telus, M., Huss, G. R., Ogliore, R. C., Nagashima, K. \& Tachibana, S. Recalculation of data for short-lived radionuclide systems using less-biased ratio estimation. Meteorit. Planet. Sci. 47, 2013-2030 (2012).

28. Deloule, E., France-Lanord, C. \& Albarède, F. D/H analysis of minerals by ion probe. in Stable isotope geochemistry: A tribute to Samuel Epstein (eds H. P. Taylor, H. P, O'Neil J. R. \& Kaplan, I. R.) 53-62 (Geochemical Society Special Publications vol 3, 1991).

29. Bureau, H., Raepsaet, C., Khodja, H., Carraro, A. \& Aubaud, C. Determination of hydrogen content in geological samples using elastic recoil detection analysis (ERDA). Geochim. Cosmochim. Acta 73, 3311-3322 (2009).

30. Xia, Q.-K., Dallai, L. \& Deloule, E. Oxygen and hydrogen isotope heterogeneity of clinopyroxene megacryst from Nushan volcano, SE China. Chem. Geol. 209, 137-151 (2004). 
514 31. Aléon, J., Engrand, C., Robert, F. \& Chaussidon, M. Clues to the origin of interplanetary

515 dust particles from the isotopic study of their hydrogen-bearing phases. Geochim.

516 Cosmochim. Acta 65, 4399-4412 (2001).

517

518 